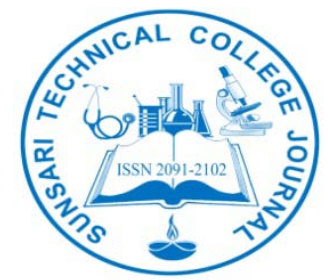

\title{
UTILIZATION OF MILK BY-PRODUCT (BUTTERMILK) IN THE PREPARATION OF CHHURPI AND ITS QUALITY EVALUATION
}

\author{
Som Raj Shrestha ${ }^{1}$, Mahalaxmi Pradhananga ${ }^{2 *}$, Suman Kumar Lal Das ${ }^{3}$ \\ ${ }^{1}$ Senior QA Executive, Bottlers Nepal Terai Limited, Bharatpur \\ ${ }^{2}$ Department of food Technology, Sunsari Technical College, Tribhuvan University, Dharan \\ ${ }^{3}$ Department of food Technology, Central Campus of Technology, Tribhuvan University, Dharan \\ *Corresponding author email: mahalaxmi.sara@gmail.com
}

Received: 11.11.2014; Revised and Accepted- 25.12.2014

DOI: http://dx.doi.org/10.3126/stcj.v2i1.14789

\begin{abstract}
Chhurpi, a traditional milk product were prepared with slight improvement in manufacturing practice; using skim milk: butter milk at different variations (SM:BM=0:100, 20:80, 40:60, 60;40. 80:20, and100:0) at $70^{\circ} \mathrm{C}$ and coagulated by $2 \%$ tartaric acid maintaining $\mathrm{pH}$ value 5.3. The formulation having ratio SM:BM of 0:100 found to be best among all the formulations except the control one and was not significantly different in terms of flavor, body and texture, gumminess and chewiness and overall acceptability. Physico- chemical analysis of best product was found to be $10 \%$ moisture, $5.26 \%$ fat, $74.17 \%$ protein, $3.18 \%$ lactose and $6.26 \%$ total ash. Chemical analysis of the best product was not significantly different in terms of lactose content and total ash content while it was significantly different in terms of moisture content, fat content and protein content from control i.e. $100 \%$ skim milk at $\mathrm{p}<0.05$. Hence, according to this research the sweet cream buttermilk as a waste of dairy industries can be solely used to convert into a value added milk product with earnings.
\end{abstract}

Keywords: buttermilk, skimmilk, chhurpi, coagulation

\section{INTRODUCTION}

Chhurpi is an indigenous product of Nepal, Eastern India and Bhutan and dried hard coagulated casein product, often called hard cheese. It is prepared by acid coagulation of curd. It is light amber to dark brown color, cubical or cylindrical block, faintly sweet but distinctly smoky with hard and compact body. The interesting characteristics of chhurpi are its gumminess and chewiness ${ }^{1}$. Chhurpi manufacture is a convenient way of converting the fat and protein of milk into nutritious product with good keeping qualities as milk into a product which is not likely to deteriorate. The appearance, flavor and texture of the finished chhurpi depend on three parameters; time, temperature, and acidity. chhurpi is an example of application of combined methods (Hurdle Technology) among shelf stable products. Heating, acid coagulation, addition of sugar and sorbate, smoking, drying, and packaging in a closed container make the product more stable $^{2}$

Buttermilk is a dairy by- product of churning cream for butter making. The composition and food value of buttermilk are essentially the same as those of skim milk. The fat content is higher in case of buttermilk. It supplies protein, riboflavin and calcium in the highest amount. It contains a large proportion of the protein mixture slouched from the fat globule- milk serum interface by churning ${ }^{3}$.

The milk for chhurpi preparation is standardized for fat to solid not fat (SNF) content of 1:8.7. Chhurpi preparation milk was heated to $70^{\circ} \mathrm{C}$ for no hold or 15 sec. The coagulation carried out at $70^{\circ} \mathrm{C}$ has significantly higher 
cohesiveness, gumminess and chewiness, compared to the sample prepared by coagulating milk at other temperature ${ }^{4}$. The whey is removed from the curd through a muslin cloth $^{5}$. Shrinkage or syneresis of coagulum causing it to lose more water and become firmer is facilitated by cooking. In chhurpi (pH 5.2-5.35) the casein is partly in the calcium form. Heating hastens the expulsion of whey from the curd, increases elasticity and changes the texture so that it is more compact and has fewer openings. Stirring at a high temperature causes a desirable physical condition of the curd which permits the whey to filter off through and among the cheese particles ${ }^{4}$.

The expulsion of water also reduces the cost of drying ${ }^{5}$. Normally, it is not possible to reduce the moisture level in the pressed curd to less than 55\%. The pressed curd should be promptly dried in order to prevent spoilage by mould and bacterial action ${ }^{4}$.The cutting shapes the chhurpi for drying. Generally chhurpi is cut in size of $12 \times 2 \times 2 \mathrm{~cm}^{3} 1$. The smoking of chhurpi is for the addition of flavor and drying improves the keeping quality. The product is formed and forms the rind to the product. Hard wood gives desirable color, taste and texture. Soft wood does not give this because it has high resin, thus taste is unpalatable ${ }^{4}$.

Normally, only $4 \mathrm{~kg}$ of chhurpi is obtained from 100 liters of milk. Optimization of traditional process condition in chhurpi making has already being carried out to shorten production time with improved and consistent texture, flavor and color increases shelf life and this in turn increase its general acceptability ${ }^{1,4}$. This problem feels a necessity of technology development for the utilization of buttermilk for edible purpose of man. Hence the present research will help for development of this technology in both of products and processing sector in some extent.

\section{MATERIALS AND METHODS}

\section{Physiochemical analysis of skim milk and buttermilk (raw)}

Acidity as lactic acid of buttermilk and skim milk were determined, $\mathrm{pH}$ of buttermilk and skim milk were determined from $\mathrm{pH}$ meter. TSS of buttermilk and skim milk were determined by lactometer. ${ }^{6}$ The lactose, Protein, Fat content and Ash content of buttermilk and skim milk was also determined . ${ }^{7}$

Processing operations The raw materials were kept at chilling temperature and were heated separately to temperature $70^{\circ} \mathrm{C}$ then mixing of samples in different formulations were made by varying the mixing ratios.

Table 1. Formulation of chhurpi at different variation

\begin{tabular}{|c|c|c|}
\hline Code & $\begin{array}{c}\text { Skim milk } \\
\text { (by parts) }\end{array}$ & $\begin{array}{c}\text { Buttermilk } \\
\text { (by parts) }\end{array}$ \\
\hline A & 0 & 100 \\
B & 100 & 0 \\
C & 60 & 40 \\
D & 80 & 20 \\
E & 40 & 60 \\
F & 20 & 80 \\
\hline
\end{tabular}

\section{Coagulation temperature of milk}

After making the variations of skimmilk: buttermilk; the temperature was again maintained to $70^{\circ} \mathrm{C}$ (for coagulation) and coagulated immediately by addition of $2 \%$ warmed tartaric acid. The coagulation was carried out till clear whey was obtained ( $\mathrm{pH}$ 5.3). About $1 / 2^{\text {nd }}$ part of whey was drained and the green curd was further cooked with the remaining whey till a creamish yellow color mass was obtained.

The hot cooked curd was wrapped in a muslin cloth (generally wrapped in hessian cloth) and was pressed in hoop $\left(9 \mathrm{~kg} / \mathrm{cm}^{2}\right.$ for $6 \mathrm{hrs}$.). The obtained mass was cut into long stripes or regular shape.

The cylindrical pieces were tied and hanged over the fire maintaining the smoke temperature about $35 \pm 5^{\circ} \mathrm{C}$ for a week. The smoke of the fire gave the Chhurpi a smoky flavor and reduced its moisture to a safe level. The product was further dried at room temperature and sundried for 30 days.

\section{Analytical analysis}

The representative samples of chhurpi were served to semitrained panelists and the sensory evaluation was done by using 9 points hedonic rating scale. The parameters for evaluation were color and appearance, flavor, body and texture, gumminess and chewiness and overall acceptability. The sensory data were analyzed by using the analysis of variance (two way ANOVA) at 5\% level of significance using genstat.

The best chhurpi samples were firstly cut into small pieces and then ground to a homogenous mass in the form of powder using motar and pestle. The mass was then used for analysis. The moisture, fat and protein content of chhurpiwas determined. ${ }^{8}$ The ash content and lactose content of chhurpi was determined according to ${ }^{6}$.

\section{RESULTS AND DISCUSSION}

\section{Analysis of buttermilk and skim milk}

Buttermilk prepared from sweet cream and skim milk was used for the product preparation. They were analyzed for their composition and the chemical analysis of buttermilk and skim milk are found as follows. 
Table 2. Chemical composition of buttermilk and skim milk

\begin{tabular}{|llll|}
\hline S. N. & Parameters & Buttermilk (\%) & $\begin{array}{l}\text { Skim milk } \\
(\%)\end{array}$ \\
\hline 1. & Acidity & $0.18(0.00)$ & $0.18(0.00)$ \\
2. & $\mathrm{pH}$ & $6.40(0.00)$ & $6.50(0.00)$ \\
3. & Lactose & $4.00(0.20)$ & $4.60(0.10)$ \\
4. & Protein & $3.40(0.10)$ & $3.60(0.05)$ \\
5. & Fat & $0.50(0.00)$ & $0.20(0.00)$ \\
6. & Ash & $0.68(0.027)$ & $0.70(0.02)$ \\
\hline
\end{tabular}

Note: Values are arithmetic mean of triplicate samples.

The data obtained above compares favorably with those in different literatures and standards. According to Nielsen and Ullum (1989),the chemical characteristics of buttermilk are as shown in table. ${ }^{9}$

The protein, lactose and ash were within the range but the TSS and fat may varied according with different factors like addition of water during churning of cream, fat \% in cream, churning temperature, etc.

\section{Coagulant}

The yield of the chhurpi prepared from using 2\% tartaric acid solution was significantly higher than the yield of the samples prepared by using 1 and 3\% concentration of the coagulants. The yield from tartaric acid was even higher than that of lactic acid of the same concentration ${ }^{5}$. Total solid loss in whey increases with increase in concentration of coagulant. Total solid loss in the whey was also affected by the $\mathrm{pH}$ of the coagulation. As the $\mathrm{pH}$ (5.3-5.35) of coagulation was kept same for all the cases, the effect might only be due to concentration difference of coagulants. The total solid recovery decreases as concentration of coagulant increases. Greater the total solid loss in whey lesser was the total solid recovery in chhurpi as it was inversely related ${ }^{1}$.

\section{Sensory Analysis:}

\section{Color and appearance}

The mean sensory score for color and appearance were found to be 7.9, 7.1, 6.3, 6.4, 5.8 and 3.9 for the different formulations A, B, C, D, E and F respectively. Control chhurpi (A) was significantly different from B, C, D, E and $\mathrm{F}$ in terms of color and appearance at the $5 \%$ level of significance. Formulation B was also significantly different from C, E and F but showed non significant difference with formulation D.

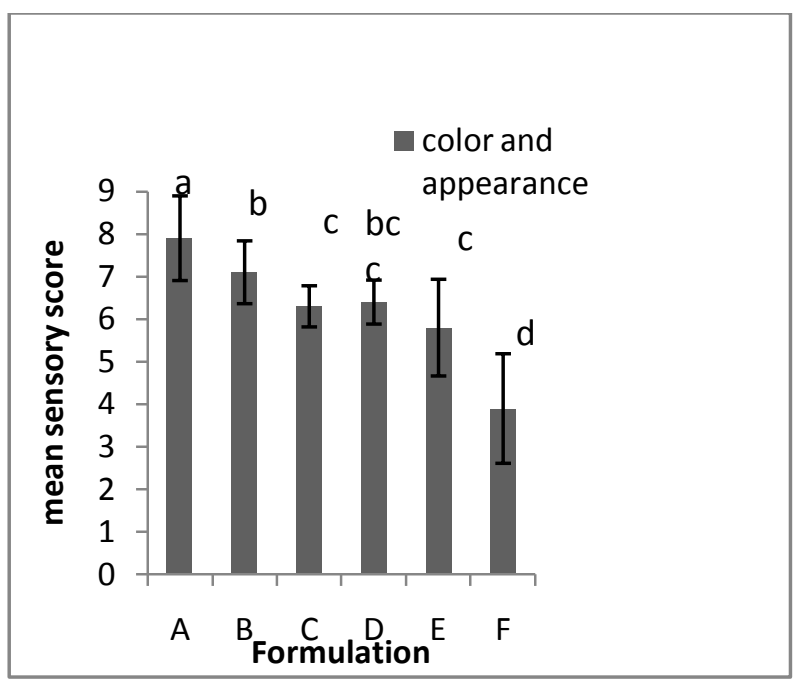

Figure 1. Histogram of mean scores for color and appearance

(Note: bars with similar alphabets at the top are not significantly different)

Flavor

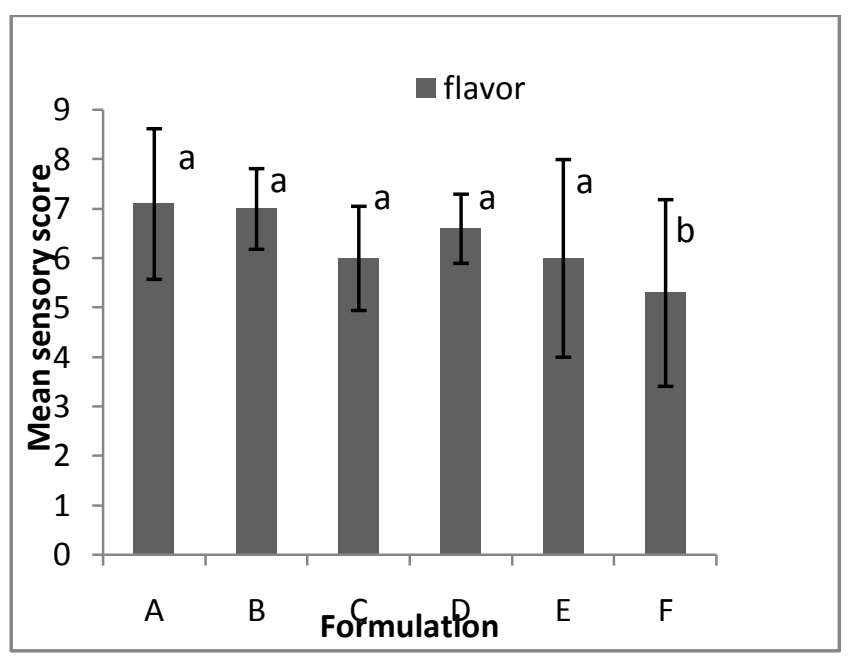

Figure 2. Histogram of mean scores for flavor

(Note: bars with similar alphabets at the top are not significantly different)

The mean sensory score for the flavor for the six different formulations were found to be 7.1, 7.0, 6.0, 6.6, 6.0 and 5.3 for $\mathrm{A}, \mathrm{B}, \mathrm{C}, \mathrm{D}, \mathrm{E}$ and $\mathrm{F}$ respectively. The mean sensory score of control sample (A) was found to be highest i.e. 7.1 among the six samples. But the control sample (A) was not significantly different from formulations B, C, D and E except sample F. 


\section{Body and texture}

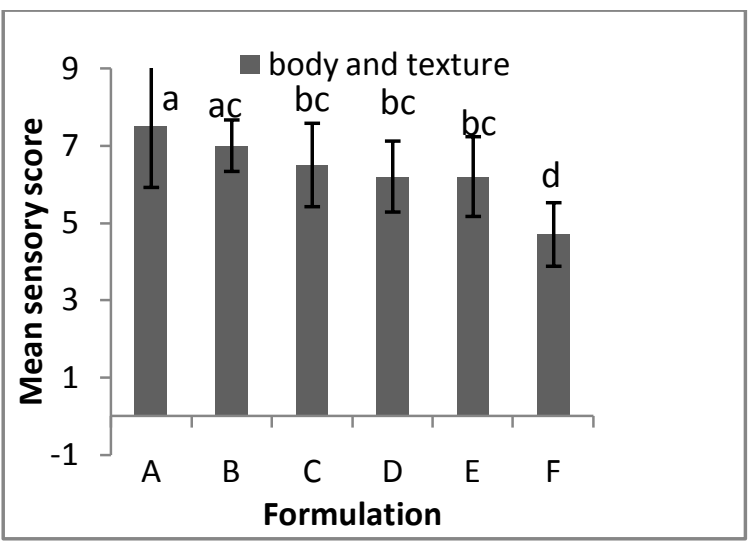

Figure 3. Histogram of mean scores for body and texture

(note: bars with similar alphabets at the top are not significantly different)

The mean score for body and texture were found to be 7.5, 7.0, 6.5, 6.2, 6.2 and 4.7 for the formulations A, B, C, D, E and $\mathrm{F}$ respectively. Statistical analysis showed that substitution of buttermilk to the skim milk produced the chhurpi with slightly different body and texture as compared to control. As in figure the control product (A) was significant different from C, D, E and F; except the formulation $\mathrm{B}$ at the $5 \%$ level of significance.

\section{Gumminess and chewiness}

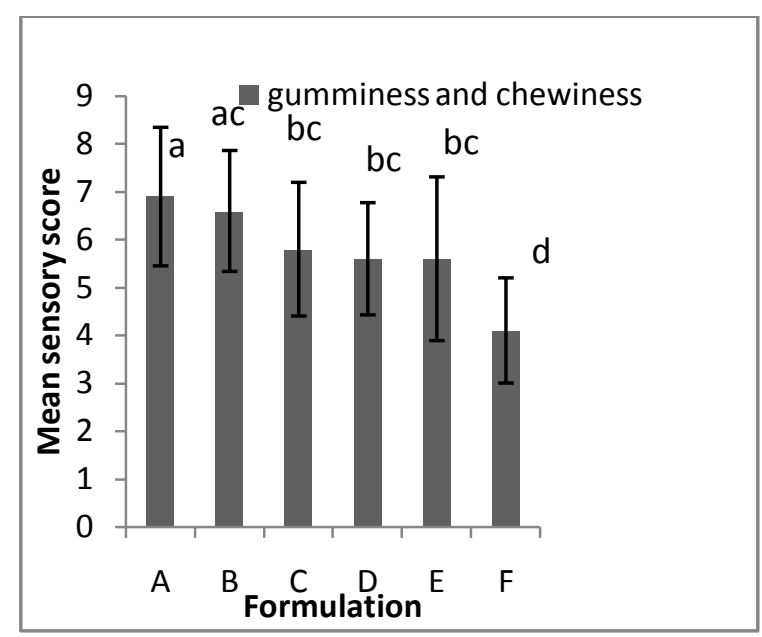

Fig. 4 Histogram of mean scores for gumminess and chewiness

(note: bars with similar alphabets at the top are not significantly different)

The mean sensory for gumminess and chewiness were found to be $6.9,6.6,5.8,5.6,5.6$ and 4.1 for the different formulations A, B, C, D, E and F respectively. As shown in the above figure the control product (A) was significantly different from C, D, E and F except B. The formulation A was significantly superior similar to sample B.

\section{Overall acceptability}

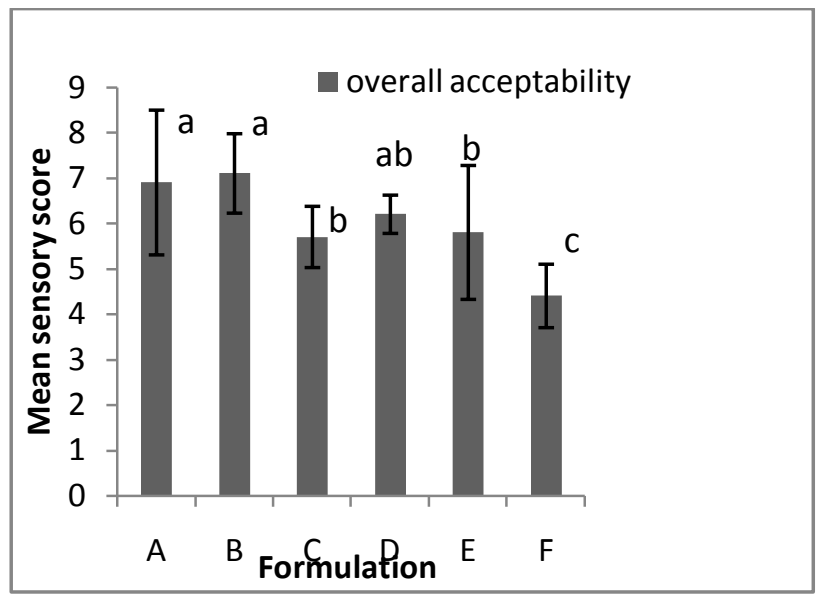

Figure 5. Histogram of mean scores for overall acceptability

(note: bars with similar alphabets at the top are not significantly different)

The above figure shows the mean sensory score for the formulations A, B, C, D, E and F having mean values 6.9, 7.1, 5.7, 6.2, 5.8 and 4.4 respectively. Statistical analysis revealed that there was no significant difference $(<0.05)$ in overall acceptability among the formulations A, B and D in terms of overall acceptability and with the mean sensory score sample B was superior.

\section{Proximate composition of control and best product}

Table 4 Proximate composition of control (100\% skim milk) and best (100\% buttermilk) chhurpi

\begin{tabular}{|llllll|}
\hline $\begin{array}{l}\text { Paramet } \\
\text { er }\end{array}$ & $\begin{array}{l}\text { Moisture } \\
(\%) \mathrm{db}\end{array}$ & $\begin{array}{l}\text { Fat } \\
(\%) \mathrm{db}\end{array}$ & $\begin{array}{l}\text { Protein } \\
(\%) \mathrm{db}\end{array}$ & $\begin{array}{l}\text { Lactose } \\
(\%) \mathrm{db}\end{array}$ & $\begin{array}{l}\text { Total } \\
\text { ash(\%)db }\end{array}$ \\
\hline Control & $\begin{array}{l}12.67 \\
(0.416)^{\mathrm{a}}\end{array}$ & $\begin{array}{l}4.67 \\
(0.116)^{\mathrm{a}}\end{array}$ & $\begin{array}{l}77.07 \\
(1.194)^{\mathrm{a}}\end{array}$ & $\begin{array}{l}3.35 \\
(0.142)^{\mathrm{a}}\end{array}$ & $\begin{array}{l}6.06 \\
(0.148)^{\mathrm{a}}\end{array}$ \\
\hline Best & $\begin{array}{l}10 \\
(0.346)^{\mathrm{b}}\end{array}$ & $\begin{array}{l}5.266 \\
(0.231)^{\mathrm{b}}\end{array}$ & $\begin{array}{l}74.17 \\
(0.832)^{\mathrm{b}}\end{array}$ & $\begin{array}{l}3.18 \\
(0.068)^{\mathrm{a}}\end{array}$ & $\begin{array}{l}6.26 \\
(0.344)^{\mathrm{a}}\end{array}$ \\
\hline $\begin{array}{l}\text { LSD } \\
(5 \%)\end{array}$ & 0.868 & 0.4135 & 2.332 & 0.2521 & 0.600 \\
\hline
\end{tabular}

Values are the means of the triplicates and figures in the parenthesis are standard deviation of the triplicate. Values in the column having different superscripts are significantly different at $5 \%$ level of significance.

The moisture content of the control and the best formulation made got low moisture content viz., 12.67 and $10 \%$ respectively. According to ${ }^{1}$ the moisture content of 
the chhurpi is about $13 \%$, but the chhupi made got lower moisture content. The lower moisture content in the chhurpi might be due to the over drying and smoking of product which was done to make it safe from the mould growth because the chhurpi was made during rainy season. Although the low moisture made the product safe from mould growth, it affected the gumminess and chewiness of the chhurpi.

The fat content of the chhurpi (both control and the best) decreased as it should be because the raw materials from which it was made were already lower in fat content. The fat content of the milk used for the chhurpi preparation should not be less than $1 \%$ but the buttermilk and skim milk brought had the fat content of 0.5 and $0.2 \%$ respectively.

The gumminess and chewiness of the chhurpiis due to the fat content and the moisture content but mostly the fat content. The chhurpi should have fat content not less than $7.7 \%{ }^{1}$. The fat content of the best formulation was slightly higher i.e. $5.266 \%$ than that of the control i.e. $4.67 \%$ one because the skim milk used for control preparation was already low in fat content i.e. $0.2 \%$ but the best product made from buttermilk was having fat percentage of 0.5 . Although high content of fat may give good mouth feel while chewing it is also very prone to rancidity and lower shelf life as compared to low fat chhurpi.

Chhurpi prepared from skim milk showed flat flavor due to negligible amount of fat content because the agreeable flavor of rich milk and of other dairy products is largely due to milk fat ${ }^{4}$.

As mentioned in the literature chhurpi have the protein content of about $68.5 \%$ on dry basis. The chhurpi we made was higher in protein content on dry basis. The control showed crude protein $77.07 \%$ while the best one had $74.17 \%$. This increased content of the protein in the product made may be due to low in fat content in the raw materials and it was obvious that the coagulated mass was rich in casein. Also the moisture content of the finished product had low obviously gave the higher protein content on dry basis.

The lactose content of the both control and the best product was almost the same $3.35 \%$ and $3.18 \%$ respectively and there was no significant different at the $5 \%$ level of significance. Both the product got the required content of lactose as they should have because the raw materials used for the preparation had good percentage of lactose which were not lost while skimming of milk and retained in buttermilk while churning of cream.

According to Pal et al., (1996) chhurpi have total ash content of about $7.0 \%{ }^{1}$ The control and the best one had the total ash content of 6.06 and $6.26 \%$ respectively. Minerals content in both the formulations were almost the same and also there was no significant different in minerals content at $5 \%$ level of significance. The minerals content of the product were not as low as fat because of retention of minerals in the buttermilk and skim milk.

Table 5. Energy value of the chhurpi per $100 \mathrm{~g}$ made from $100 \%$ buttermilk

\begin{tabular}{|ll|ll|}
\hline Nutrients & $\begin{array}{l}\text { Quantity } \\
(\mathrm{g})\end{array}$ & Energy/gm & $\begin{array}{l}\text { Total } \\
\text { energy } \\
\text { (Kcal) }\end{array}$ \\
\hline Carbohydrate & 3.18 & 4.0 & 12.72 \\
Protein & 74.17 & 4.0 & 296.68 \\
Fat & 5.266 & 9.0 & 47.39 \\
& & & $\begin{array}{l}\text { Total }= \\
356.79\end{array}$ \\
\hline
\end{tabular}

\section{CONCLUSIONS}

Buttermilk as a dairy by-product can be used for the nutritious masticatory food item. The product can emerge as a new technology in itself if modern method can be applied. The conversion of dairy by-product to such a protein rich food could be a great recovery from economical loses of dairy industries. Hence from the present work, it will help to develop the processed buttermilk product and encourage to work and technically study on buttermilk. Optimization of this traditional process condition in chhurpi making is carried to shorten the production time and also the increased in shelf life. Better quality product with characteristics gumminess and chewiness can be obtained by standardization of raw material ie. Fat : SNF ratio of 1:8.7. From the sensory score provided by the 10 semi-panelist using 9-point hedonic rating test, chhurpi prepared from 100\% buttermilk was found to be the best one among other formulations as compared to control.

\section{ACKNOWLEDGEMENT}

We would like to express humble gratitude to all the staff of Central Campus of Technology, Hattisar, Dharan-14. We are also grateful to the Central Department of Food Technology for all the help provided.

\section{REFERENCES}


1. Pal, P.K., Hossain, S. A. and Sarkar, P. K. Optimization of process parameters in the manufacture of chhurpi. J. Food Sci. Tech., 1996; 33: 219-223.

2. Pal, P. K. Technological and biochemical innovations in manufacturing chhurpi, a traditional South East Asian milk product. Ph. D. Thesis, Univ. of North Bengal, Siliguri., India. 1994

3. Dangol, D. Preparation and evaluation of fermented beverage from buttermilk. B. Tech. (Food) unpublished Dissertation. Central Campus of Technology. Tribhuvan Univ. Dharan. 2005

4. Gupta, S. and Acharya, P. P. Effects of coagulants on the chemical composition and product quality of chhurpi. Npl. J. Food Sci. Tech., 1999; 1: 15-18.
5. Bastola, A. Effect of agar, carboxymethylcellulose and guar gum on yield and quality of paneer. B. Tech. (Food) Dissertation. Central Campus of Technology. Tribhuvan Univ. Dharan. 2001

6. Pearson, D. The Chemical Analysis of Foods, $7^{\text {th }}$ Edn. Churchill Living Stone , Edinburgh, London and New York. 1991.

7. Kharel, G. P., Acharya, P. P. and Rai, B.K. Milk products,In:"Handbookof Traditional foods of Nepal”, 2007; 22-25.

8. Rai, B. K. Traditional fermented foods. In: “Industrial Microbiology”, 2006; 255-274.

9. Nielsen, E. W. and Ullum, J. A. Basic principles of cheese making. In: "Dairy Technology 2", Danish Turnkey Dairies Ltd, 1989; 122-124.

Cite this article as: Shrestha S R, Pradhananga M L , Das S K L. Utilization of milk by-product (Buttermilk) in the preparation of Chhurpi and its quality evaluation. STCJ 2015;2(1):1-6 